\title{
On-Chip Tungsten Oxide Nanowires Based Electrodes for Charge Injection
}

\author{
Anil Ağıral and J. G. E. (Han) Gardeniers \\ Mesoscale Chemical Systems, MESA+ Institute for Nanotechnology, \\ University of Twente Enschede, \\ The Netherlands
}

\section{Introduction}

Transition metal oxides are fundamental to the development of many potential applications in nanoelectronics, optoelectronics and sensor devices (Wang, 2003 and Simon et al., 2001). Nanostructured metal oxides are widely investigated for scientific and technological applications. For example, binary semiconducting oxides have distinctive properties as transparent conducting oxide materials (Pan et al., 2001). Nanowires, which are stimulated by carbon nanoubes, have attracted wide interest due to their potential for bringing basic issues like dimensionality and transport phenomena in nanoscale dimensions. Among the transition metal oxide nanowires, tungsten oxide nanorods/nanowires show good sensing and field emission (FE) properties. FE from tungsten oxide nanowires shows good stability and high emission current density due to large aspect ratio, low turn-on field and stability at high pressures of 10-6-10-3 Torr (Kim et al., 2005 and Seelaboyina et al., 2006). Synthesis methods for tungsten oxide nanowires include heating and oxidation of tungsten filaments (Liu et al., 2005), foils or films in vacuum at temperatures above $1000^{\circ} \mathrm{C}$ (Liu et al, 2003 and Cho et al., 2004). To the best of our knowledge, there are no studies atmospheric pressure FE performances of tungsten oxide nanowires. Synthesis of uniform and crystalline $\mathrm{W}_{18} \mathrm{O}_{49}$ nanowires on tungsten thin films by thermal annealing in ethane and nitrogen will be described in the first part of this chapter. Growth mechanism and atmospheric pressure FE analysis of a diode device based on nanowires will be discussed. The oxides have mixed cation valences and an adjustable oxygen deficiency which form the bases for tuning the electrical, chemical, optical and magnetic properties.

In the second part of this chapter, application of tungsten oxide nanowires in a miniaturized plasma device will be demonstrated. Miniaturized plasma sources have generated wide interest, recently, due to a number of important applications, light sources and chemical reactors (Becker et al., 2006). Performing an atmospheric pressure plasma process in a microreactor leads to precise control of process parameters such as residence time and heat transfer, and also extreme quenching conditions, enabling control over the reactants to selectively produce desirable products (Nozaki et al., 2004). $\mathrm{W}_{18} \mathrm{O}_{49}$ nanowires gave outstanding field emission characteristics with low threshold voltages due to local field enhancement and high aspect ratio (Guillorn et al., 2001 and Zhou et al., 2005). Process of

Source: Nanowires, Book edited by: Paola Prete,

ISBN 978-953-7619-79-4, pp. 414, March 2010, INTECH, Croatia, downloaded from SCIYO.COM 
field emission and field ionization can supply free electrons and ions and it can contribute to a pre-breakdown current during the initiation of streamer of discharge. It was shown previously that multiplication of electrons in a series of impact ionizations can lower the breakdown voltage in microplasma devices (Park \& Eden, 2004). Eden et al. incorporated multiwall carbon nanotubes (CNTs) into the cathode and it resulted in lowering the ignition voltage and increasing the radiative efficiency. It was also reported that field emitted electrons can vibrationally excite molecules near a surface and lower the activation energy for dissociative adsorption (Tas, 1995). In order to test the contribution of FE from tungsten oxide nanowires during atmospheric pressure microplasma production, $\mathrm{W}_{18} \mathrm{O}_{49}$ nanowires on a silicon chip electrode placed in a glass microreactor channel will be described. The characteristics of dielectric barrier discharge with $\mathrm{W}_{18} \mathrm{O}_{49}$ nanowires will be reported and compared with plane-to-plane electrodes without nanostructures.

\section{Synthesis of tungsten oxide nanowires}

Tungsten oxide nanowires were grown in a quartz reactor with a glass plate to support ntype Si (100) (1- $10 \mathrm{Ohm} \mathrm{cm}$ ) samples, on which a $300 \mathrm{~nm}$ thick tungsten film was deposited by DC plasma sputtering from a $99.999 \%$ pure tungsten target. The temperature was monitored with a single thermocouple positioned just above the samples. Gases were mixed at atmospheric pressure, flushed through the tube furnace, collected and analyzed with an online gas chromatography. The whole chemical vapour deposition (CVD) apparatus is shown in Fig. 1.

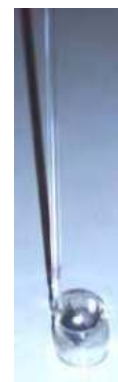

(a)

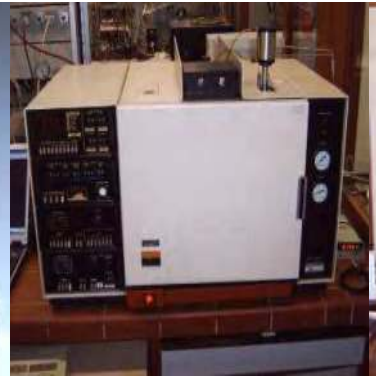

(b)

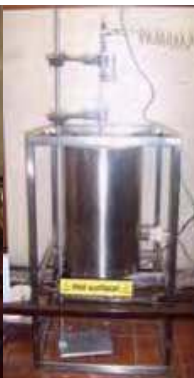

(c)

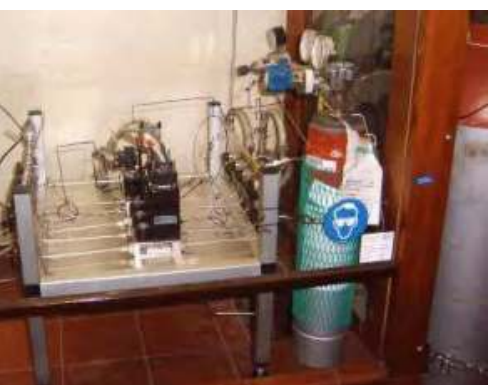

(d)

Fig. 1. CVD setup for tungsten oxide growth apparatus with (a) the sample holder with two samples, (b) gas chromatography, (c) the tube furnace and (d) the gas supply with flow controllers and mixing board.

In a typical growth procedure, samples were loaded at room temperature. Then the temperature was increased with a ramp of $6^{\circ} \mathrm{C} / \mathrm{min}$. When the desired growth temperature was reached, the carbon (gas) source was opened while the ouput gas composition was monitored. No pre-treatment procedure was needed. When the hyrogen production was detected in the chromatogram, it is evidence that hydrocarbon gas was dissociated on the tungsten film. The sample was heated in $\mathrm{N}_{2}(80 \mathrm{sccm})$ and ethene was introduced in order to start nanowire growth for 20 mins. After nanowire growth, ended by switching off the carbon source, the temperature was ramped down with $10^{\circ} \mathrm{C} / \mathrm{min}$ until the temperature was $400^{\circ} \mathrm{C}$. At this temperature, the heater was switched off resulting in passive cooling process. 
Chemical characterization of nanowires was carried out by using scanning electron microscopy (SEM) (LEO 1550 FEG) and high resolution tranmission electron microscopy (HRTEM) equipped with EDX analysis (Philips CM300ST-FEG microscope) and selected area diffraction (SAD). X-ray Photoelectron spectroscopy (XPS) analysis was also carried out in a PHI Quantera Scanning ESCA Microprobe system.

Atmospheric pressure FE measurements were performed in a microfabricated diode device in a laminar air flow cabinet at room tempereture. n-type silicon substrates were oxidized to form $\mathrm{SiO}_{2}$ as dielectric spacer and the oxide was etched with HF solution isotropically to create a rectangular window, with an area of $0.7 \mathrm{~cm}^{2}$, which was defined by photolithography. $2 \mu \mathrm{m}$ thermal oxide was grown at $1150{ }^{\circ} \mathrm{C}$ in a wet $\left(\mathrm{H}_{2} \mathrm{O}\right)$ ambient oxidation process for 10 hours. The oxide thickness was verified by ellipsometry using two wavelengths (632.8 and $1552 \mathrm{~nm}$ ), and turned out to be around $1945 \mathrm{~nm}$. When a large voltage is applied at an electrode, a leakage current may flow between cathode and anode through the oxide layer. In order to check the oxide quality, the leakage current was measured using special test structures. $W$ dots were sputtered on oxidized $\mathrm{n}^{++}$substrates $(2$ $\mu \mathrm{m}$ oxide) using a shadow mask and the back of wafer was sputter coated with $200 \mathrm{~nm}$ platinium $(\mathrm{Pt})$. Wafers were $\mathrm{HF}$ dipped $(1 \%, 1 \mathrm{~min})$ prior to the platinium deposition, tungsten dots were deposited after platinium sputtering. These samples were not subjected to high temperature processes. The leakage current was measured at one stop with the back of the wafer as second electrode using an Agilent 4145 IV meter in combination with a Microtech Cascade probe station. A typical result is shown in Fig. 2:

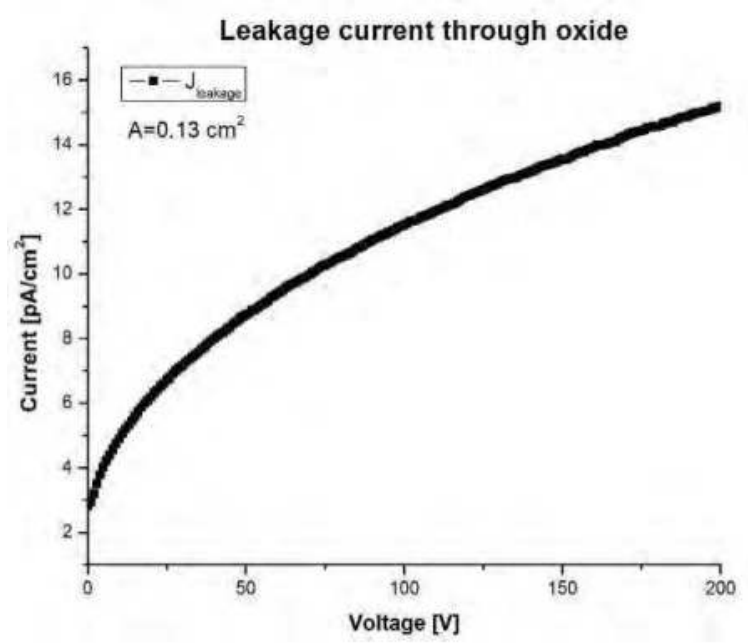

Fig. 2. Leakage current through oxide $(2 \mu \mathrm{m})$ for a typical tungsten spot ( $4 \mathrm{~mm} \varnothing)$.

This figure indicates that the gate leakage current is very low; in the range of $\mathrm{pA} / \mathrm{cm}$.

$\mathrm{SiO}_{2}$ layer was etched with $\mathrm{HF}$ solution in order to form dielectric spacer between nanowires and anode electrode in the diode device. After wet etching of $\mathrm{SiO}_{2}$, a tungsten film was sputtered into the window. After nanowires growth on the cathode, the silicon substrate with a $10 \mathrm{~nm}$ gold layer as extractor electrode was clamped to the cathode to ensure a $2-\mu \mathrm{m}$ electrode distance in a diode structure. Voltage current data were obtained with a Keithley 237 source meter unit. 


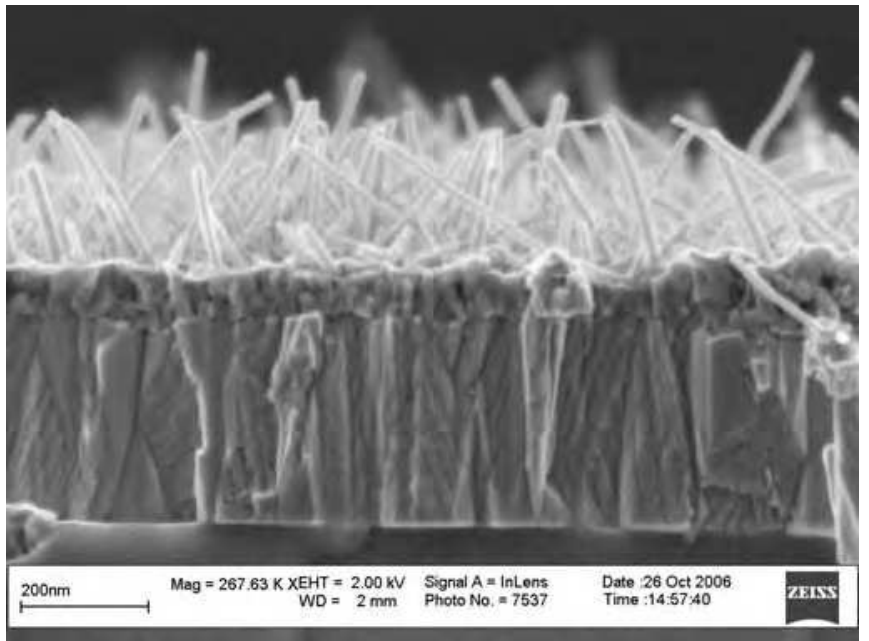

Fig. 3. Cross section SEM image of tungsten oxide nanowires grown on tungsten thin films exposed to $27 \mathrm{sccm}$ of $\mathrm{C}_{2} \mathrm{H}_{4}$ and $80 \mathrm{sccm}$ of $\mathrm{N}_{2}$ at $700^{\circ} \mathrm{C}$ at atmospheric pressure.

Fig. 3 shows a SEM image of tungsten oxide nanowires which were grown on tungsten thin films exposed to $27 \mathrm{sccm}$ of of $\mathrm{C}_{2} \mathrm{H}_{4}$ and $80 \mathrm{sccm}$ of $\mathrm{N}_{2}$ at $700^{\circ} \mathrm{C}$ at atmospheric pressure. Nanowires were grown uniformly with high yield on the tungsten thin film with diameters and average length in the range of $15-20 \mathrm{~nm}$ and $50-250 \mathrm{~nm}$, respectively.

To further illuminate the microstructure of as-deposited films, nanowires were also grown on both sides of freestanding tungsten thin films fabricated based on gated FE structure. Fig. 4 shows the etch profile of the silicon dioxide with freestanding tungsten thin film. In order to create the device, three main steps in the process flow were developed. First step is the photolithography, making a large array of holes of $2 \mu \mathrm{m}$ in diameter with acceptable uniformity requires a high level of control of the lithographic process. In the single mask process one layer of photoresist was used as etch mask for both gate and oxide etch steps. Final device is compatible with high temperature nanowire growth step and survive thermal stress problems (e.g. adhesion, stability). For the substrate selection for nanowire growth, silicon substrates were chosen. As the charge carriers in field emitters are electrons, the doping of the silicon substrate is taken into consideration. Highly doped wafers were selected as they minimize the substrate resistance. In p-type silicon the number of electrons (minority charge carriers) is limited by thermal generation which might give rise to current saturation at high fields during field emission. By choosing for a highly doped n-type substrate, these effects are avoided. Therefore highly doped n-type wafers were selected as substrates. These one side polished $100 \mathrm{~mm}$ silicon wafers have arsenic (As) doping, (100)orientation, a thickness of $525 \pm 25 \mu \mathrm{m}$ and a resistivity of $0.001-005 \Omega \mathrm{cm}$. Prior to processing, wafers were cleaned in the standard cleaning. Before oxidation, wafers were were dipped in $1 \% \mathrm{HF}$ to remove native oxide.

Thermal oxidation resulted in a $2 \mu \mathrm{m}$ high quality oxide as shown in Fig. 4 and cross section SEM image of tungsten oxide nanowires growth on both sides of freestanding thin films. Thin films have parallel ridges, which is a characteristic feature of sputtered tungsten films (Gosnet et al., 1989), covered with a dense nodular nanostructure at the tungsten/nanowire interface. 


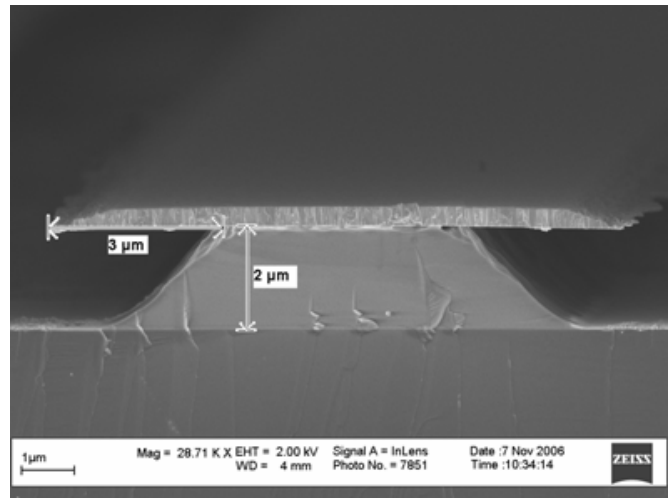

Fig. 4. Cross section SEM image of tungsten oxide nanowires grown on tungsten thin films exposed to $27 \mathrm{sccm}$ of $\mathrm{C}_{2} \mathrm{H}_{4}$ and $80 \mathrm{sccm}$ of $\mathrm{N}_{2}$ at $700^{\circ} \mathrm{C}$ at atmospheric pressure.

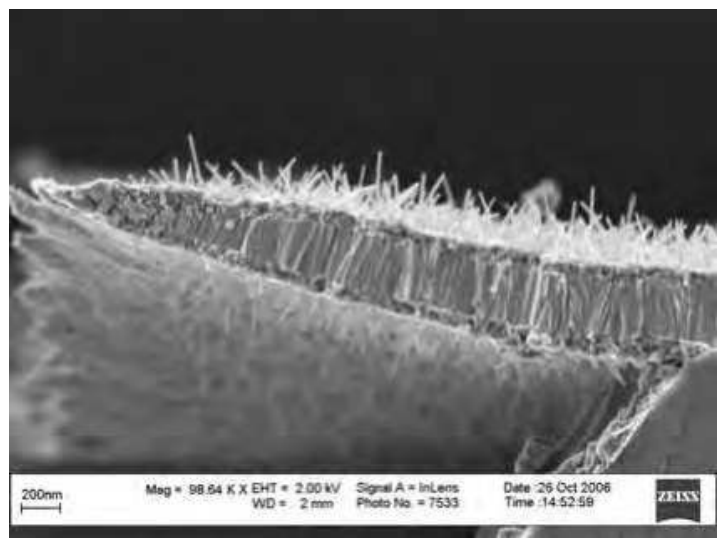

Fig. 5. Cross section SEM image of tungsten oxide nanowires grown on tungsten thin films exposed to $27 \mathrm{sccm}$ of $\mathrm{C}_{2} \mathrm{H}_{4}$ and $80 \mathrm{sccm}$ of $\mathrm{N}_{2}$ at $700^{\circ} \mathrm{C}$ at atmospheric pressure nanowire growth on both sides of freestanding thin films.

Fig. 6 shows the samples before and after nanowires growth. Sample was covered with black substance which was formed during ethylene dissociation into carbon and flow pattern of the gases can be seen around the sample during the growth. Nanowires can be seen grown on the gate electrode.

$\mathrm{X}$-ray diffraction analysis on the bulk sample indicated characteristic peaks for $\mathrm{WO}_{3-\mathrm{x}}$ a$\mathrm{W}_{2} \mathrm{C}, \beta-\mathrm{W}, \mathrm{a}-\mathrm{W}$ and $\mathrm{Si}$. $\mathrm{WO}_{3}$ and $\mathrm{W}_{18} \mathrm{O}_{49}$ show similar peaks which are difficult to distinguish in diffractogram, therefore SAD and HRTEM analyses were used to determine chemical structure and composition. From the HRTEM images in Fig. 7, it is derived that the d-spacing along the long side of the nanowire is $3.78 \AA$, which is in agreement with the SAD analysis and corresponds to the (010) plane of monoclinic $\mathrm{W}_{18} \mathrm{O}_{49}$ (JCPDS no. 36-0101). (Agiral \& Gardeniers, 2008). EDX analysis was performed on the central part of the area of nanowires which confirmed that oxygen is in the order of 2.73 times the amount of tungsten, supporting the evidences found in HRTEM and SAD measurements. Interfacial phase 


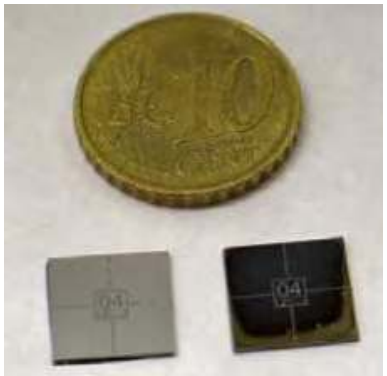

(a)

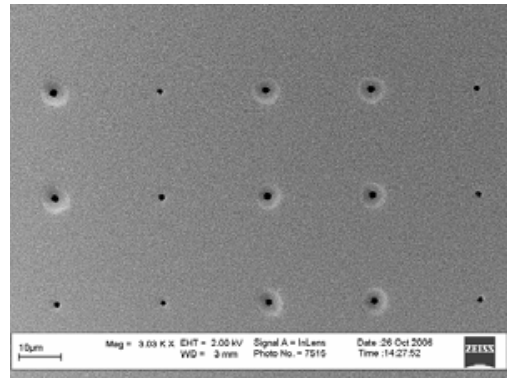

(b)

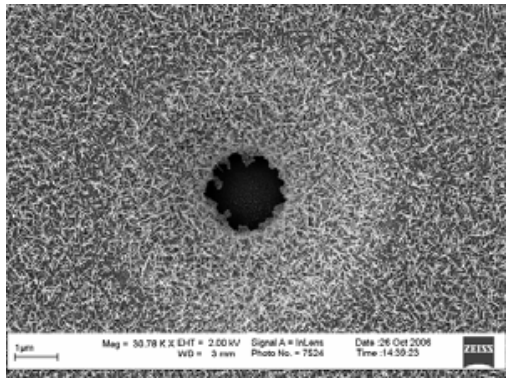

(c)

Fig. 6. Samples before (left) and after (right) the nanowires growth process. (b, c) SEM images of growth experiments on gated field emitters.
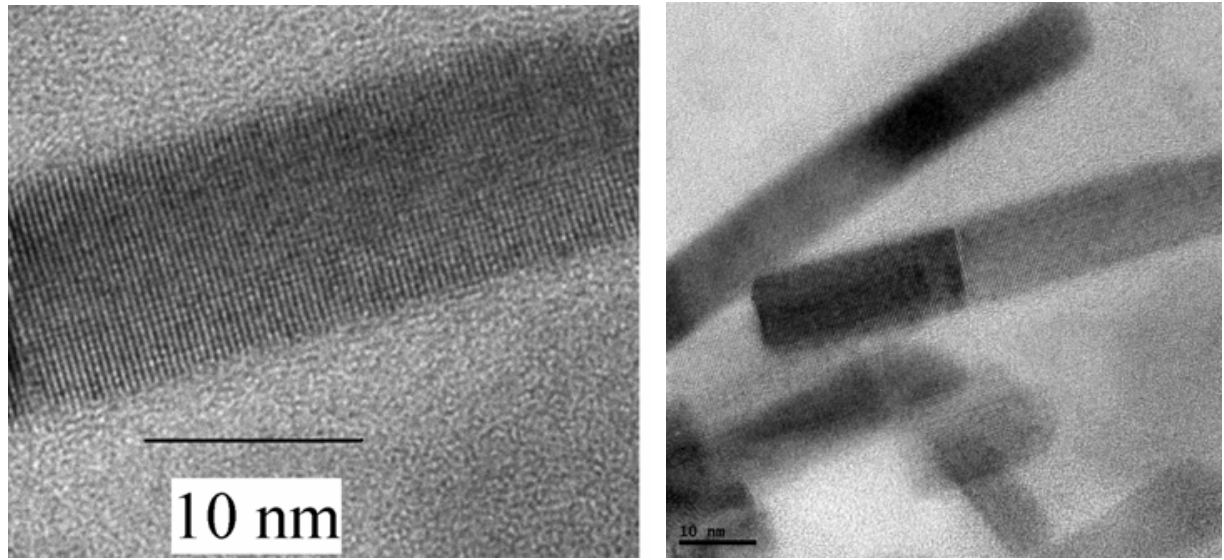

Fig. 7. HRTEM image of $\mathrm{W}_{18} \mathrm{O}_{49}$ nanowires [Agiral].

between nanowires and tungsten thin film was analyzed by SAD and it was found out that interfacial phase has d-spacings $2.36 \AA$ and $1.36 \AA$ corresponds to the phases $\alpha-W_{2} C(002)$ and $\mathrm{a}-\mathrm{W}_{2} \mathrm{C}(103)$, respectively (Wang et al., 2004).

Chemical bonding states on the surface of the tungsten thin film and the nanowires were investigated by XPS (not shown). W 4f spectra were deconvoluted into Lorentzian-Gaussian 


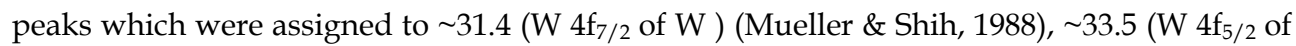
W) (Rogers et al., 1982), 33.2 ( $\mathrm{W}_{4} \mathrm{f}_{7 / 2}$ of $\left.\mathrm{W}^{4+}, \mathrm{WO}_{2}\right)$ (Salvati et al., 1981), $35.3\left(\mathrm{~W}_{4} \mathrm{f}_{5 / 2}\right.$ of

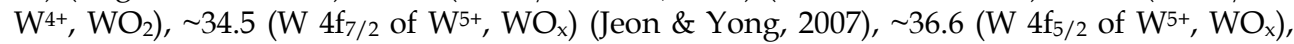
$\sim 35.7\left(\mathrm{~W}_{4} \mathrm{f}_{7 / 2}\right.$ of $\left.\mathrm{W}^{6+}, \mathrm{WO}_{3}\right)$ (Fleisch \& Mains, 1982), $\sim 37.8\left(\mathrm{~W}_{4} \mathrm{f}_{5 / 2}\right.$ of $\left.\mathrm{W}^{6+}, \mathrm{WO}_{3}\right)$. It was observed that after nanowire growth, the intensity ratio of binding states of oxidized tungsten to metallic tungsten increased, which is consistent with $\mathrm{W}_{18} \mathrm{O}_{49}$ formation. A low intense peak at about $31.7 \mathrm{eV}$ was assigned to tungsten carbide $\mathrm{W}_{4} \mathrm{f}_{7 / 2}$ which is possibly bound in the nanowires/film interface (Katrib et al., 1994).

Oxygen on the tungsten thin film originally comes from the native oxide layer that was formed when the sample exposed to the atmosphere. It was reported that molecular oxygen in the air can dissociatively chemisorb with oxygen atoms at triply-coordinated sites (Feydt et al., 1999). In order to determine the effect of chemisorbed oxygen present on the tungsten surface, thin film was reduced by introducing hydrogen at $700{ }^{\circ} \mathrm{C}$ for $20 \mathrm{~min}$ before nanowire growth. After ethene exposure, a dramatic decrease in the number of nanowires was observed. These results show the fact that tungsten oxide nanowire growth was caused by the oxygen bound on the surface. Carbon deposition rate, ethene dissociation and hydrogen evolution during nanowire growth were followed by online gas chromatography. It was found out that (Agiral \& Gardeniers, 2008) dissociation of ethane into carbon and hydrogen took place according to the reaction:

$$
\mathrm{C}_{2} \mathrm{H}_{4(\mathrm{~g})} \leftrightarrow 2 \mathrm{C}_{(\mathrm{s})}+2 \mathrm{H}_{2(\mathrm{~g})}
$$

A solid-state reaction took place between tungsten and deposited carbon in order to form a tungsten carbide phase during nanowire growth:

$$
2 \mathrm{~W}_{(\mathrm{s})}+\mathrm{C}_{(\mathrm{s})} \leftrightarrow \mathrm{W}_{2} \mathrm{C}_{(\mathrm{s})}
$$

Examination of the role of tungsten carbide phase for nanowire formation in the presence of only pure nitrogen indicated the fact that without ethene gas the nanowires could only grow with very low yield. Since tungsten carbide was not incorporated in the nanowires, it is assumed that it promoted nucleation and the growth. Vapor-solid and Vapor-Liquid-Solid growth models could not be explanations since the nanowires were formed with most of the oxygen on the tungsten surface and there were no nanoparticles at the end of the nanowires (Wang et al., 2005 \& Wagner \& Ellis, 1964). Here, tungsten carbide formation at the $\mathrm{W} / \mathrm{WO}_{\mathrm{x}}$ interface enhances the strain which drives whisker formation for nanowire growth. In -situ hydrogen formation during ethene dissociation can contribute to enhance oxygen diffusion especially through the grain boundaries. $\mathrm{W}_{18} \mathrm{O}_{49}$ nanowires can grow on dislocation sources which originate from the defects along the grain boundaries. Nanowires growth is enhanced by the interfacial strain created by tungsten carbide formation (Agiral \& Gardeniers, 2008).

\section{Atmospheric pressure field emission properties of $\mathrm{W}_{18} \mathrm{O}_{49}$ nanowires}

Atmospheric pressure field emission measurements of tungsten oxide nanowires were done in air for a contact gap close to $2 \mu \mathrm{m}$. The mean free path of an electron in air is close to $2 \mu \mathrm{m}$ (Hopwood \& Iza, 2004) and probability of ionization from collisions of gas particles with FE electrons is very limited in this diode type device. However, only few collisions which develop positive ions in front of nanowires can even increase the current density (Schwirzke et al., 1993). 
Fig. 8 illustrates the field emission measurements. The macroscopic current density $J_{M}$ $\left(\mathrm{mA} / \mathrm{cm}^{2}\right)$ was calculated to be the emission current $(I)$ divided by the surface area of the diode window $\left(A_{M}=\right.$ macroscopic film area) on the cathode $\left(0.7 \mathrm{~cm}^{2}\right)$. The macroscopic electric field $F_{M}(\mathrm{~V} / \mu \mathrm{m})$ was defined as the applied voltage divided by the electrode gap ( 2 $\mu \mathrm{m})$ between the cathode and the gold coated anode. The FE turn-on field is ca. $3.3 \mathrm{~V} / \mu \mathrm{m}$ and defined as the electric field required to extract a current density of $10 \mu \mathrm{A} / \mathrm{cm}^{2}$. The $J_{M^{-}}$ $F_{M}$ plotted in Fig. 8 shows the FE diode characteristics for 3 consecutive sweeps (plots a-b-c) of negative cathode voltage. The exponential dependence of current density on electric field suggests a FE process taking place. A similar experiment performed using a parallel plate diode structure (tungsten surface as cathode) without nanowires did not show rectification behavior (plot d).

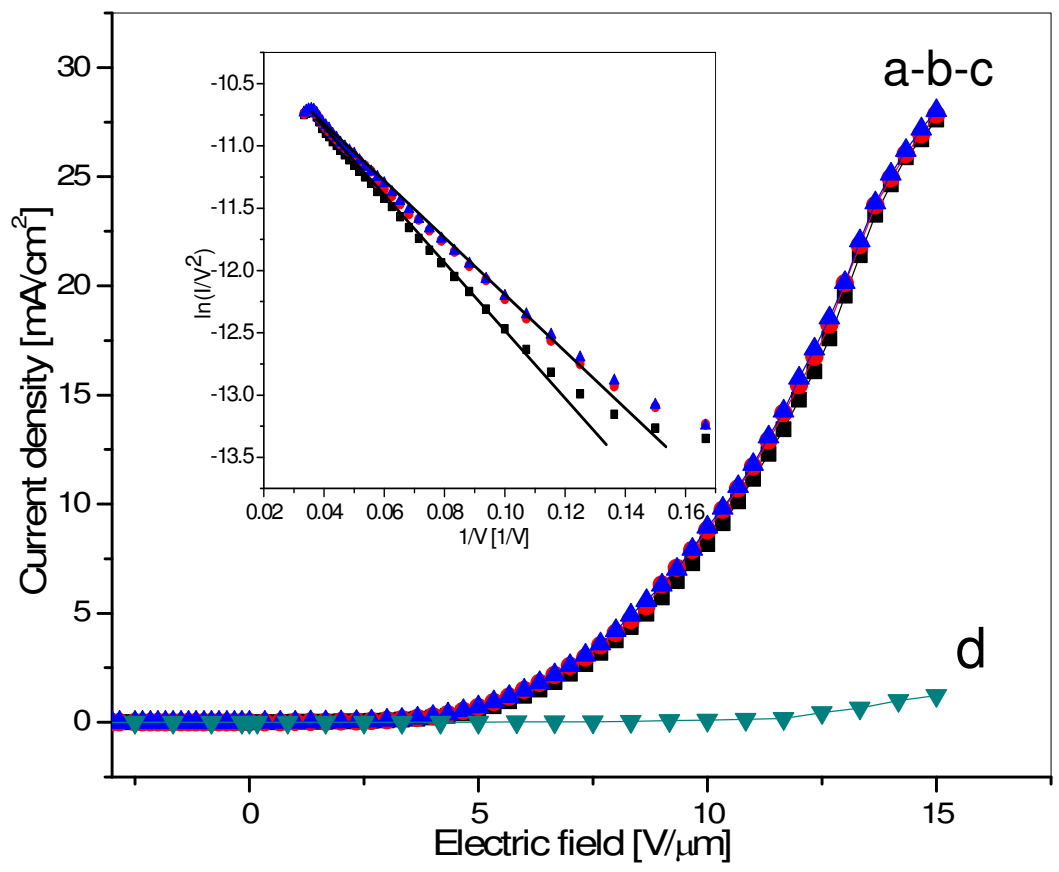

Fig. 8. Atmospheric pressure FE properties of tungsten oxide nanowires measured in air for a contact gap $\sim 2 \mu \mathrm{m}$. The macroscopic current density vs. macroscopic electric field $\left(J_{M}-F_{M}\right)$ plots a-b-c correspond to 3 consecutive sweeps of negative cathode voltage with nanowires, while plot $\mathrm{d}$ shows the results of a parallel-plate diode without nanowires (insets are the corresponding Fowler Nordheim plots) (Agiral and Gardeniers, 2008).

The emission characteristics were analyzed by standard Fowler-Nordheim (FN) tunneling theory using the current-density equation (Forbes et al., 2007):

$$
J=\left[\tau_{F}^{-2} a \varphi^{-1} F^{2}\right] \exp \left[-v_{F} b \varphi^{3 / 2} / F\right]
$$


where the 'first Fowler-Nordheim constant' $a=e^{3} / 8 \pi h_{p}=1.541434 \times 10^{-6} \mathrm{AeVV}^{-2}$, 'second Fowler-Nordheim constant' $b=(8 \pi / 3)\left(2 m_{e}\right)^{1 / 2} / \mathrm{eh}_{p}=6.830890 \times 10^{9} \mathrm{eV}^{-3 / 2} \mathrm{Vm}^{-1}, e$ is the elementary positive charge, $m_{e}$ is the electron mass, $h_{p}$ is Planck's constant, $J$ is local current density, $F$ is local field, $\varphi$ is local work function of emitting surface, $\tau_{F}$ and $v_{F}$ are the values of $\tau$ (decay rate correction factor) and $v$ (tunneling exponent correction factor) which apply to a barrier of unreduced height $h$ equal to the local work function $\varphi$. For the elementary triangular barrier, the correction factors $v$ and $\tau$ are set equal to unity. Assuming that the local work function is uniform, the emission current $I$ can be written as $I=A_{N} J$, where $\mathrm{A}_{\mathrm{N}}$ is notional emission area. This gives:

$$
I=A_{N} J=A_{N} \tau_{F}^{-2} a \varphi^{-1} F^{2} \exp \left[-v_{F} b \varphi^{3 / 2} / F\right]
$$

Geometric field enhancement may lead to the local field $F$ to be greater than $F_{M}$ by a factor $(\gamma)$ which is called the field enhancement factor:

$$
r=F / F_{M}
$$

In the literature, FN plots from tungsten oxide nanowires are analyzed using FN theory for metals (Huang et al., 2007). If the macroscopic electric field $F_{M}$ is used as FN variable in Eq. (4) to replace F, the formula can be written as:

$$
\ln \left[I / F_{M^{2}}\right]=\ln \left[A_{N} \tau_{F}^{-2} a \varphi^{-1} \gamma^{2}\right]-\left[v_{F} b \varphi^{3 / 2} / \gamma\right] / F_{M}
$$

The theoretical model for a FN plot is the tangent to Eq. (6), taken at $\mathrm{F}_{\mathrm{M} 1}$ of macroscopic field (Forbes, 2001):

$$
\ln \left[I / F_{M^{2}}\right]=\ln \left[A_{N} r_{1} a \varphi^{-1} \gamma^{2}\right]-\left[s_{1} b \varphi^{3 / 2} / \gamma\right] / F_{M}
$$

where $r_{1}$ and $s_{1}$ are the generalized intercept correction factor and the generalized slope correction factor, respectively, taken at field $\mathrm{F}_{\mathrm{M} 1}$ (Forbes, 1999). $s_{1}$ is approximately 1 and therefore omitted in the interpretation of the slope of the FN plot. Assuming that the emission current comes mainly from one band, and $\varphi$ is $5.7 \mathrm{eV}$, similar to $\mathrm{WO}_{3}$, the field enhancement factor found from the FN plot is 7228 .

Estimation of the apex field-enhancement factor $\gamma$ of a protrusion on a flat planar surface has been described with 'hemisphere on a post' and 'hemi-ellipsoid on a plane' models (Forbes et al., 2003). Both these geometrical models can be applied to tungsten oxide nanowires, considering their geometry. The 'hemisphere on a post' model gives the simple formula:

$$
\gamma=0.7(L / \rho)
$$

where $L$ and $\rho$ are protrusion length and base radius, respectively. In the 'hemi-ellipsoid on a plane' model $\gamma$ can be written as:

$$
r=\zeta^{3} /[(v \ln (v+\zeta))-\zeta]
$$

where $L$ is the semi-major axis length, $\rho$ is the semi-minor axis length, $v(=L / \rho)$ is the ratio of $L$ to $\rho$ and $\zeta$ equals $\left(v^{2}-1\right)^{1 / 2}$. If the formula of the 'hemisphere on a post' model for a nanowire of $15 \mathrm{~nm}$ diameter and $250 \mathrm{~nm}$ length is used, $\gamma$ is calculated to be around 23 which is far below the experimental field enhancement factor. However, SEM and HRTEM analysis revealed that there are few nanowires on the sample with length and diameter of $\sim 1$ $\mu \mathrm{m}$ and $\sim 12 \mathrm{~nm}$, respectively. Applying the 'hemi-ellipsoid on a plane' formula, $\gamma$ can be 
calculated to be 5776, which is of the order of the experimental value. A small part of the sample surface may have protruding nanowires with longer length and smaller diameter than the average dimensions.

At high electric fields $(>13 \mathrm{~V} / \mu \mathrm{m}), J_{M}$ diverged from the Fowler-Nordheim equation where saturation affects were observed and eventually breakdown occurred around $15.2 \mathrm{~V} / \mu \mathrm{m}$.

Emission stability of nanowires was also measured at $13.6 \mathrm{~V} / \mu \mathrm{m}$, however no significant degradation in emission current was observed over 1 hour of testing period. Current fluctuations can be attributed to surface chemical interactions with adsorbents which can affect the tunneling state of nanowires or residual ions impacting on the surface. In order to demonstrate the viability of tungsten oxide nanowires as a pulsed electron source, a $100 \mathrm{~Hz}$ square wave voltage was applied to the cathode and pulsed electron emission with good repetition rate was observed.

As the $F_{M}$ reached the value of $15.2 \mathrm{~V} / \mu \mathrm{m}$, breakdown occurred. SEM analysis (not shown) on the surface is suggestive of an explosive FE process due to the presence of craters on the cathode surface and melted film traces on the anode surface. Possible mechanisms for explosion of emitter can be high density FE currents, resistive heating and the Nottingham mechanism. Nottingham effect can arise when temperature inside the emitters increases faster than that of the surface, due to the energy difference between emitted electrons and their replacement in the lattice through the electrical circuit. Under these conditions, temperature can rise to a critical level and a phase transition of the field emitters into a dense plasma and loss of cathode material is observed.

\section{Incorporation of nanostructures into microplasma reactor}

As an application example, tungsten oxide nanowires were incorporated in a glass microchannel to generate barrier discharge between the nanowires and a copper foil electrode protected by a glass dielectric layer. $250 \mathrm{~nm}$ titanium-tungsten alloy and $50 \mathrm{~nm}$ tungsten metal layers were deposited on silicon chips by plasma sputtering. Silicon chips with $\mathrm{W}$ layers were placed in the CVD setup to grow nanowires as mentioned in the previous sections. Silicon chips with nanowires were placed in glass microreactors with rectangular cross section of $50 \mathrm{~mm}$ in length and $20 \mathrm{~mm}$ in width. To finish the fabrication of whole device, microchannels, inlet and outlet holes for gas flow were created by powder blasting and the glass layers were thermally bonded to seal the microchannel hermetically. Fig. $9 a$ and $9 b$ show the final devices. Fig. 9c shows the general diagram of device and operating plasma device is shown in Fig. 9d.

A combination of a high voltage amplifier (Trek 610E) and a function generator (Agilent $3322 \mathrm{~A}$ ) was used to generate a barrier discharge at $1 \mathrm{kHz}$ in the microreactor. Voltage drop across a resistor and a capacitor connected in series with the electrodes were used to calculate the transferred current and charge, respectively. Light emission from the discharge was collected by an optical fiber inserted into microchannel and optical fiber was connected to an optical emission spectrometer (HR 4000, Ocean optics). Lissajous figures measured with an oscilloscope were evaluated in order to calculate the absorbed power by discharge. The amount of current that is transferred across the gap is also much higher in the case of microreactor with nanowires electrode. The reduction of breakdown voltage and increase in transferred current is suggesting electric field amplification and emission of electrons on the nanowires surface. Electric field in the gas gap of microreactor $(5 \mathrm{~V} / \mu \mathrm{m})$ is enough to generate field emitted electrons before breakdown. Work functions of planar and tungsten 
oxide nanowires surfaces are similar since there is a native oxide layer a few nanometer thickness on the tungsten film.

Comparison of power absorbed by the discharge as a function of measured voltage shows that at the same measured voltage, a higher energy density microdischarge was generated with the nanowires due to generation of higher number of streamers in the gas gap. Local electric field enhancement on the surface helps to increase the number of streamers and microplasma became more homogeneous.
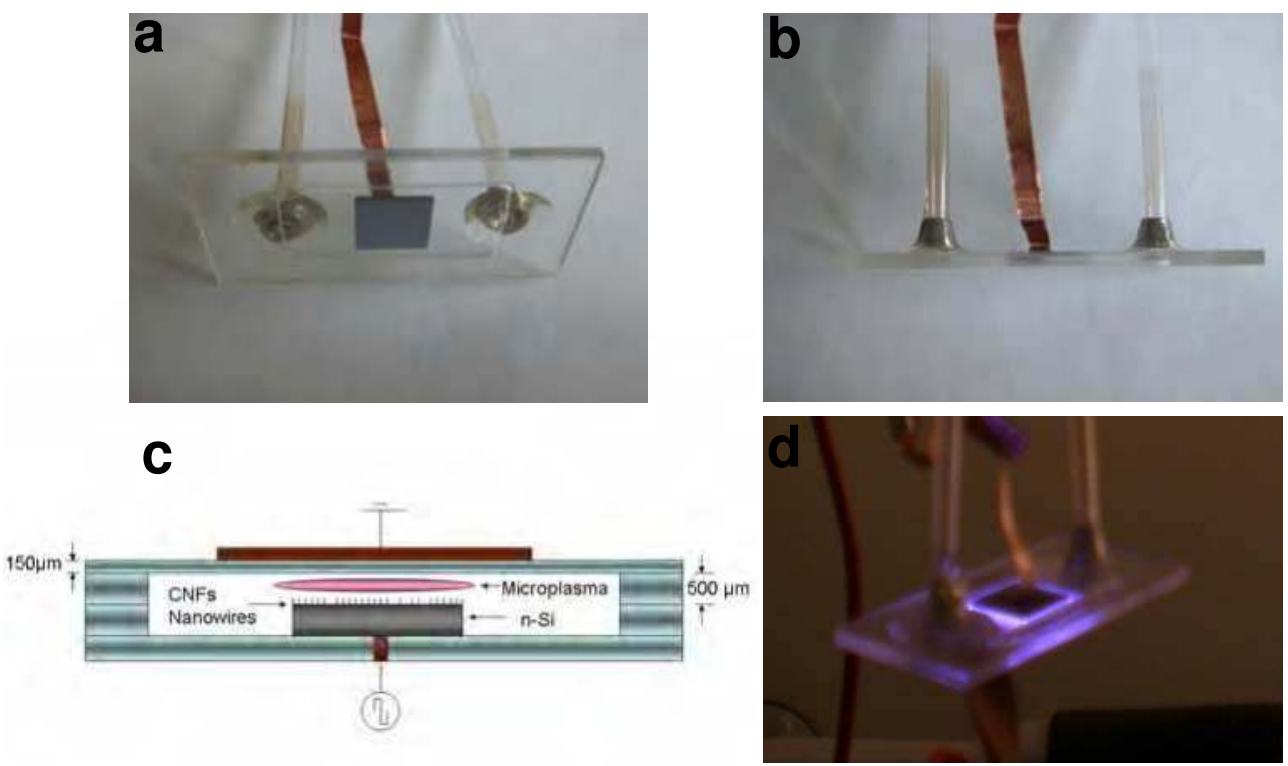

Fig. 9. Microplasma reactors with integrated tungsten oxide nanowires electrode (a) and (b). General diagram of microreactor (c) and the plasma device in operation (Agiral et al., 2008).
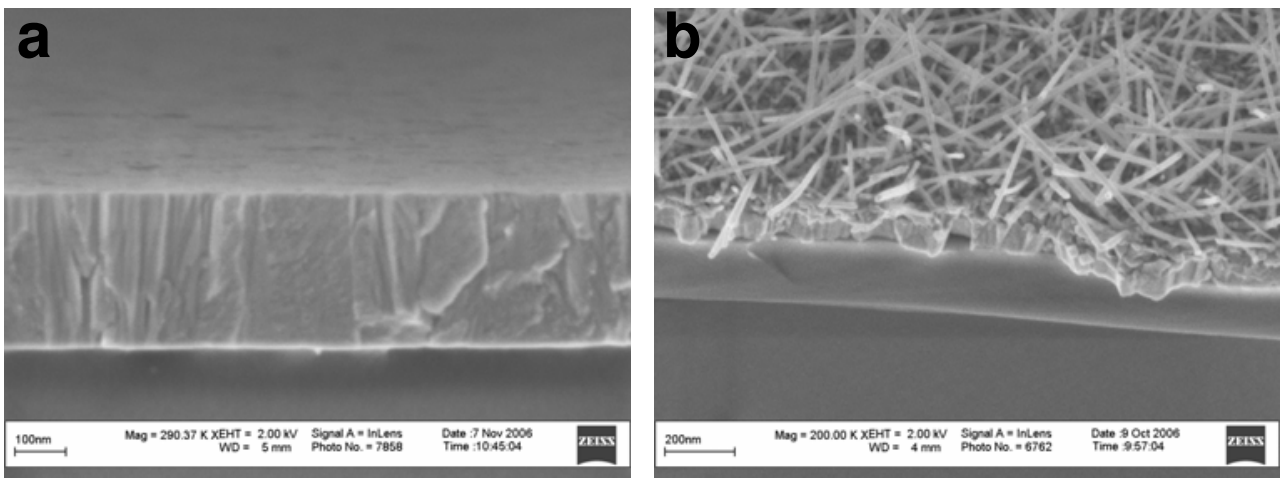

Fig. 10. SEM images of planar tungsten thin film electrode (a) and electrode covered with tungsten oxide nanowires (b). 
In order to analyze light emission from microplasma, an optical fiber coupled to the emission spectrometer, inserted into microchannel. In case of nanowires, the intensity of the emission lines is found to be much higher than planar electrodes. Jani et al. (Jani et al., 1999) analyzed the variation of electron temperature by spectroscopic measurement using the second positive system of $\mathrm{N}_{2}(337.1 \mathrm{~nm})$ and the first negative (FNS) of $\mathrm{N}_{2}{ }^{+}(391.4 \mathrm{~nm})$. It was shown that the ratio of the SPS to the FNS changes with electron temperature in the discharge, and the intensity ratio of the lines increase with increasing average electron energy. In our case, intensity ratio was calculated to be 0.061 and 0.058 for nanowires and planar electrodes, respectively, which shows no remarkable difference although the intensity of the emission lines is much higher for the spectrum for nanowire electrode at the same applied voltage.

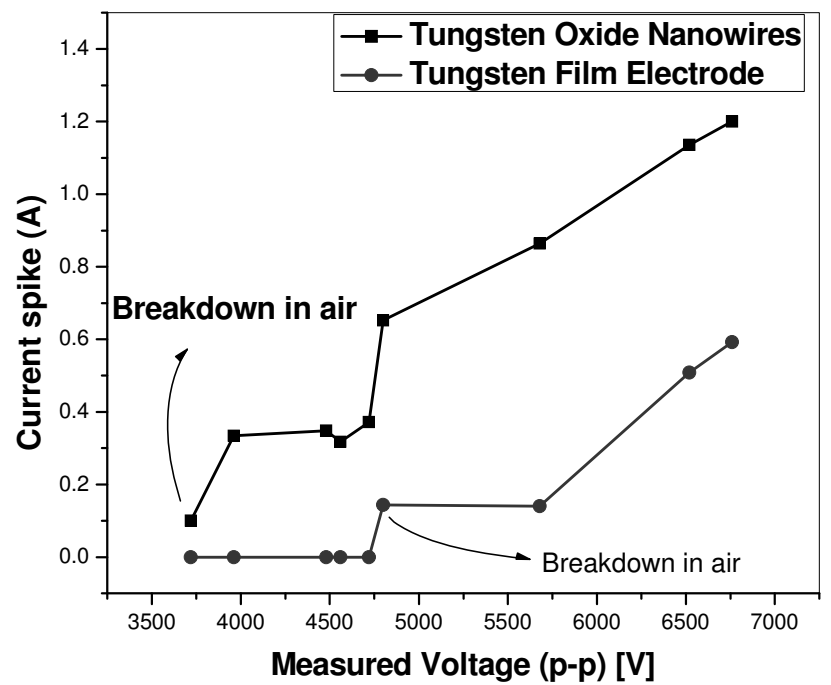

Fig. 11. Comparison of discharge current spikes measured with tungsten oxide nanowires and with a planar tungsten film electrode for varying applied peak-to-peak voltage; $f=1$ $\mathrm{kHz}$. Points show the current measured with oscilloscope at corresponding measured voltage values. Breakdown voltage is defined as voltage level at which light emission was detected by optical emission spectrometer (Agiral et al., 2008).

\section{Conclusion}

In summary, uniform and highly crystalline $\mathrm{W}_{18} \mathrm{O}_{49}$ nanowires were successfully grown with high yield on sputter deposited tungsten films by thermal annealing at $700^{\circ} \mathrm{C}$ in ethene and nitrogen at atmospheric pressure. It has been shown that tungsten carbide $\left(\mathrm{W}_{2} \mathrm{C}\right)$ formation at the surface of the tungsten film increased the nucleation and growth of nanowires by generating dislocation sources and interfacial strain. Field emission measurements at atmospheric pressure indicated that stable atmospheric pressure field emission and pulsed field emission took place in air at a current density up to $28 \mathrm{~mA} / \mathrm{cm}^{2}$. The field emission current obeyed the Fowler-Nordheim equation. 
A microplasma reactor having tungsten oxide nanowires as electrodes were fabricated in a barrier discharge configuration. Field enhancement at the apex of the tips of nanostructures resulted in electron emission at atmospheric pressure in air. For nanowires, a decrease in breakdown voltage during barrier discharge generation resulted in a higher number of microdischarges and a higher power deposition at the same measured potential compared to planar cathodes.

\section{References}

Wang, Z. L. (2003) Nanobelts, Nanowires, and Nanodiskettes of Semiconducting OxidesFrom Materials to Nanodevices. Adv. Mater., 15, 432.

Simon, I.; Bârsan, N.; Bauer, M. \& Weimar, U. (2001). Micromachined metal oxide gas sensor: opportunities to improve sensor performance. Sens. Actuators B, 73, 1 .

Pan, Z. W.; Dai, Z. R. \& Wang, Z. L. (2001). Nanobelts of semiconducting oxides. Science, 291, 1947.

Kim, Y. S.; Ha, S.-C.; Kim, K.; Yang, H.; Choi, S.-Y.; Kim,Y. T.; Park, J. T.; Lee, C. H.;

Choi, J.; Paek, J. \& Lee, K. (2005). Room temperature semiconductor gas sensor base don stoichiometric tungsten oxide nanorod film. Appl. Phys. Lett., 86, 213105.

Seelaboyina, R.; Huang, J.; Park, J.; Kang, D. H. \& Choi, W. B. (2006). Multistage field enhancement of tungsten oxide nanowires and its field emission in various vacuum conditions. Nanotechnology, 17, 4840.

Liu, K.; Foord, D. T. \& Scipioni, L. (2005). Easy growth of undoped and doped tungsten oxide nanowires with high purity and orientation, Nanotechnology, 16, 10.

Liu, Z.; Bando, Y. \& Tang, C. (2003). Synthesis of tungsten oxide nanowires, Chem. Phys. Lett., 372, 179.

Cho, M. H. et al. (2004). Evolution of tungsten oxide whiskers synthesized by a rapid thermal annealing treatment. J. Vac. Sci. Technol. B, 22, 1084.

Becker K. H., Schoenbach K. H. \& Eden J. G., (2006). Microplasmas and applications J. Phys. D: Appl. Phys., 39, R55.

Nozaki T., Hattori A. \& Okazaki K., (2004). Partial oxidation of methane using a microscale non-equilibrium plasma reactor. Catal. Today, 98, 607.

Guillorn M. A., Melechko A. V., Merkulov V. I., Ellis E. D., Britton C. L., Simpson M. L., Lowndes D. H. \& Baylor L. R., (2001). Operation of a gated field emitter using and individual carbon nanofiber cathode, Appl. Phys. Lett., 79, 3506.

Zhou J., Gong L., Deng Z., Chen J., She J. C., Xu N. S., Yang R. \& Wang Z. L. (2005). Growth and field emission property of tungsten oxide nanotip arrays. Appl. Phys. Lett., 87, 223108.

Park S. J. \& Eden J. G. (2004). Carbon nanotube enhanced performance of microplasma devices. Appl. Phys. Lett., 84, 4481.

Tas, M. A. (1995) Plasma Induced Catalysis: PhD Thesis (Technical University of Eindhoven) p 14 .

Gosnet, A. M. H.; Ladan, F. R.; Mayeux, C.; Launois, H. \& Jancour, M. C. (1989). Stress and microstructure in tungsten sputtered thin films. J. Vac. Sci.Technol. A, 7, 2663.

Agiral, A. \& Gardniers, J.G.E. (2008). Synthesis and atmospheric pressure field emission operation of W18O40 nanorods. Journal of Physical Chemistry C., 112, 39. 
Wang, S. J.; Chen, C. H.; Chang, S. C.; Uang, K. M.; Juan, C. P. \& Cheng, H. C. (2004). Growth and characterization of tungsten carbide nanowires by thermal annealing of sputter deposited WCx films. Appl.Phys. Lett., 85, 12, 2358.

Mueller, D. \& Shih, A. (1988). A Synchotron radiation study of BaO Films on W(001) and their interaction with $\mathrm{H}_{2} \mathrm{O}, \mathrm{CO}_{2}$ and $\mathrm{O}_{2}$. J. Vac. Sci. Technol. A, 6, 1067.

Rogers, J. D.; Sundaram, V. S.; Kleiman, G. G.; Castro, C. G. C.; Douglas, R. A. \& Peterlevitz, A. C. (1982). High resolution study of M45N67N67 and M45N45N67 Auger transitions in the 5D series. J. Phys. F., 12, 2097.

Salvati, L.; Makovsky, L. E.; Stencel, J. M.; Brown, F. R. \& Hercules, D. M. (1981). Surface spectroscopic study of tungsten alumina catalysts using $\mathrm{x}$-ray photoelectron, ion scattering, and raman spectroscopies. J. Phys. Chem., 85, 3700.

Jeon, S. \& Yong, K. (2007). Direct synthesis pf W18O49 nanorods from W2N film by thermal annealing. Nanotechnology, 18, 245602.

Fleisch, T. H. \& Mains, G. J. (1982). An XPS study of the UV reduction and photochromism of MoO3 and WO3. J. Chem. Phys., 76, 780.

Katrib, A.; Hemming, F.; Hilaire, L.; Wehrer, P. \& Maire, G. (1994). XPS studies of supported tungsten carbides. J. Electron Spectrosc. Relat. Phenom., 68, 589-595.

Feydt, J.; Elbe, A.; Egelhard, H.; Meister, G. \& Goldmann, A. (1999). Normal emission photoelectron studies of the $\mathrm{W}(110)(1 \times 1) \mathrm{O}$ surface. Surf. Sci., 440, 213.

Wang, S. J.; Chen, C. H.; Ko, R. M.; Kuo, Y. C.; Wong, C. H.; Wu, C. H.; Uang, K. M.;

Chen, T. M. \& Liou, B. W. (2005). Preparation of tungsten oxide nanowires from sputter deposited WCx films using an annealing/oxidation process. Appl. Phys. Lett., 86, 263103.

Wagner, R. S. \& Ellis, W. C. (1964). Vapour-liquid-solid mechanism of single crystal growth. Appl. Phys. Lett., 4, 89.

Hopwood, J.; Iza, F. (2004). Ultrahigh frequency microplasmas from 1 pascal to 1 atmosphere. J. Anal. At. Spectrom., 19, 1145-1150.

Schwirzke, F.; Hallal, M. P. \& Maruyama, X. K. (1993). Onset of breakdown and formation of cathode spots. IEEE Trans. Plasma Sci., 21, 410-415.

Forbes, R. G. \& Deane, J. H. B. (2007). Reformulation of the standard theory of FowlerNordheim tunnelling and cold field electron emission. Proc. R. Soc. A, 463, 2907-2927.

K. Huang, et al. (2007). Synthesis and field emission properties of the tungsten oxide nanowire arrays. Physica E, doi:10.1016/j.physe.2007.04.007.

Forbes, R. G. (1999). Field emission:New theory for the derivation of emission area from a Fowler-Nordheim plot. J. Vac. Sci. Technol. B, 17(2), 526-533.

Forbes, R. G. (2001). Low macroscopic field electron emission from carbon films and other electrically nanostructured heterogeneous materials:hypotheses about emission mechanism. Solid-State Electronics, 45, 779-808.

Forbes, R. G.; Edgcombe, C. J. \& Valdré, U. (2003). Some comments on models for field enhancement. Ultramicroscopy, 95, 57-65.

Agiral, A.; Groenland, A. W.; Chinthaginjala, J. K.; Seshan, K.; Lefferts, L. \& Gardeniers, J. G. E. (2008). On-chip microplasma reactors using carbon nanofibers and tungsten oxide nanowires as electrodes. Journal of Physics D: Applied Physics, 41, 194009.

Jani M. A.; Takaki K. \& Fujiwara T., (1999). Streamer polarity dependence of NOx removal by dielectric barrier discharge with a multipoint to plane geometry. J. Phys. D: Appl. Phys., 32, 2560. 


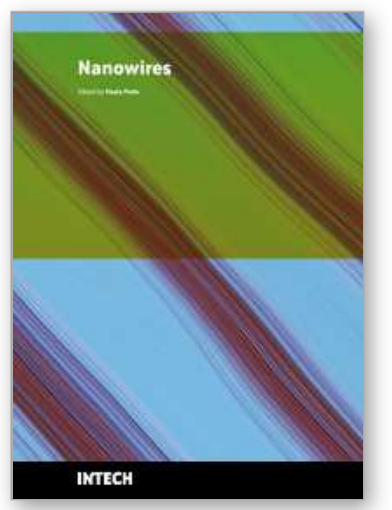

\author{
Nanowires \\ Edited by Paola Prete
}

ISBN 978-953-7619-79-4

Hard cover, 414 pages

Publisher InTech

Published online 01, February, 2010

Published in print edition February, 2010

This volume is intended to orient the reader in the fast developing field of semiconductor nanowires, by providing a series of self-contained monographs focusing on various nanowire-related topics. Each monograph serves as a short review of previous results in the literature and description of methods used in the field, as well as a summary of the authors recent achievements on the subject. Each report provides a brief sketch of the historical background behind, the physical and/or chemical principles underlying a specific nanowire fabrication/characterization technique, or the experimental/theoretical methods used to study a given nanowire property or device. Despite the diverse topics covered, the volume does appear as a unit. The writing is generally clear and precise, and the numerous illustrations provide an easier understanding of the phenomena described. The volume contains 20 Chapters covering altogether many (although not all) semiconductors of technological interest, starting with the IV-IV group compounds ( $\mathrm{SiC}$ and SiGe), carrying on with the binary and ternary compounds of the III-V (GaAs, AIGaAs, GaSb, InAs, GaP, InP, and GaN) and II-VI ( $\mathrm{HgTe}, \mathrm{HgCdTe}$ ) families, the metal oxides ( $\mathrm{CuO}, \mathrm{ZnO}, \mathrm{ZnCoO}$, tungsten oxide, and $\mathrm{PbTiO}$ ), and finishing with $\mathrm{Bi}$ (a semimetal).

\title{
How to reference
}

In order to correctly reference this scholarly work, feel free to copy and paste the following:

Anıl Agıral and J. G. E. (Han) Gardeniers (2010). On-Chip Tungsten Oxide Nanowires Based Electrodes for Charge Injection, Nanowires, Paola Prete (Ed.), ISBN: 978-953-7619-79-4, InTech, Available from: http://www.intechopen.com/books/nanowires/on-chip-tungsten-oxide-nanowires-based-electrodes-for-chargeinjection

\section{INTECH}

open science | open minds

\section{InTech Europe}

University Campus STeP Ri

Slavka Krautzeka 83/A

51000 Rijeka, Croatia

Phone: +385 (51) 770447

Fax: +385 (51) 686166

www.intechopen.com

\section{InTech China}

Unit 405, Office Block, Hotel Equatorial Shanghai

No.65, Yan An Road (West), Shanghai, 200040, China 中国上海市延安西路65号上海国际贵都大饭店办公楼 405 单元

Phone: $+86-21-62489820$

Fax: +86-21-62489821 
(C) 2010 The Author(s). Licensee IntechOpen. This chapter is distributed under the terms of the Creative Commons Attribution-NonCommercialShareAlike-3.0 License, which permits use, distribution and reproduction for non-commercial purposes, provided the original is properly cited and derivative works building on this content are distributed under the same license. 